\title{
Modification of $\mathrm{Ni}(111)$ reactivity toward $\mathrm{CH} 4, \mathrm{CO}$, and $\mathrm{D} 2$ by two-dimensional alloying
}

\author{
Holmblad, Peter Mikal; Nielsen, Jane Hvolbæk; Chorkendorff, Ib
}

Published in:

Journal of Chemical Physics

Link to article, DOI:

$10.1063 / 1.471395$

Publication date:

1996

Document Version

Publisher's PDF, also known as Version of record

Link back to DTU Orbit

Citation (APA):

Holmblad, P. M., Nielsen, J. H., \& Chorkendorff, I. (1996). Modification of $\mathrm{Ni}(111)$ reactivity toward $\mathrm{CH} 4, \mathrm{CO}$, and D2 by two-dimensional alloying. Journal of Chemical Physics, 104(18), 7289-7295.

https://doi.org/10.1063/1.471395

\section{General rights}

Copyright and moral rights for the publications made accessible in the public portal are retained by the authors and/or other copyright owners and it is a condition of accessing publications that users recognise and abide by the legal requirements associated with these rights.

- Users may download and print one copy of any publication from the public portal for the purpose of private study or research.

- You may not further distribute the material or use it for any profit-making activity or commercial gain

- You may freely distribute the URL identifying the publication in the public portal

If you believe that this document breaches copyright please contact us providing details, and we will remove access to the work immediately and investigate your claim. 


\title{
Modification of $\mathrm{Ni}(111)$ reactivity toward $\mathrm{CH}_{4}, \mathrm{CO}$, and $\mathrm{D}_{2}$ by two-dimensional alloying
}

\author{
P. M. Holmblad, J. Hvolbæk Larsen, and I. Chorkendorff \\ Physics Department, Technical University of Denmark, DK-2800 Lyngby, Denmark
}

(Received 12 September 1995; accepted 1 February 1996)

\begin{abstract}
Alloying $\mathrm{Au}$ into the outermost atomic layer of $\mathrm{Ni}(111)$ significantly alters the physical and chemical properties of the surface. The reactivity is investigated by the use of seeded supersonic molecular beams of $\mathrm{CH}_{4}$ and it is found that the nobleness of Au reduces the overall reactivity toward $\mathrm{CH}_{4}$. This is accounted for in an ensemble model resolving the sticking probability on $\mathrm{Ni}$ atoms having different nearest neighbor surroundings. Although a mean field description of site distributions is found to be a very good approximation it is improved by using experimentally determined ensemble statistics from STM images. The strong influence of the vibrational temperature on the sticking coefficients of $\mathrm{CH}_{4}$ vs translational energy on the pure $\mathrm{Ni}(111)$ is also demonstrated. Desorption energies of $\mathrm{CO}$ and $\mathrm{D}_{2}$ is observed to decrease approximately 25-30 $\mathrm{kJ} / \mathrm{mole}$ as the coverage of $\mathrm{Au}$ is increased from 0.0 to 0.7 ML. In TPD spectra of deuterium saturated surface alloys a new clearly resolved desorption state is observed at 180-220 K with maximum intensity around $\theta_{\mathrm{Au}}=0.3-0.4 \mathrm{ML}$. This state is clearly related to chemisorption sites involving both $\mathrm{Au}$ and $\mathrm{Ni}$. A site model based on mean field statistics adequately accounts for the appearance of this state. The effect of $\mathrm{Au}$ is also evident in the TPD spectra of CO saturated $\mathrm{Au} / \mathrm{Ni}(111)$ surface alloys where the saturation coverage decreases and new structure develops.

(C) 1996 American Institute of Physics. [S0021-9606(96)03717-4]
\end{abstract}

\section{INTRODUCTION}

Experimental and theoretical surface science have provided invaluable understanding of the physical properties and chemical reactivity of metal surfaces important in heterogeneous catalysis. Alloy surfaces are currently receiving a growing interest, moving the field of surface science closer toward the long term goal of atomic level design of catalysts with particular catalytic properties. ${ }^{1}$

For long it has been clear that alloying can modify the catalytic activity and selectivity of a metal. ${ }^{2-4}$ However, the influence of ensemble effects, structural effects and electronic or ligand effects on the catalyst properties are far from well understood since detailed knowledge of the surface composition was not always accessible. By the use of scanning tunneling microscopy (STM) detailed insight into the surface structure on the atomic level has become available and fundamental understanding of the reactivity of alloy surfaces can be obtained. ${ }^{5}$

It has turned out that metal on metal growth is more complex than expected from macroscopic considerations. Monolayer growth of Au on Ni single crystal surfaces is such an example. ${ }^{6-9}$ Although $\mathrm{Au}$ and $\mathrm{Ni}$ are essentially immiscible at temperatures below $600 \mathrm{~K}$ this system has recently been shown to form stable surface alloys where Au atoms substitute $\mathrm{Ni}$ atoms in the topmost atomic layer of the $\mathrm{Ni}$ surface already at the lowest coverages. Except for a weak repulsion between $\mathrm{Au}$ atoms at low coverages $\left(\theta_{\mathrm{Au}}<0.2\right.$ $\mathrm{ML})$, the $\mathrm{Au} / \mathrm{Ni}(111)$ system $^{5,8,9}$ forms a surface alloy where the $\mathrm{Au}$ atoms are nearly randomly distributed (1 $\mathrm{ML}=1.86 \times 10^{15} \mathrm{~cm}^{-2}$ ). Above $0.3 \mathrm{ML}$ the alloying induces misfit dislocation loops in the second atomic layer forming triangular structures arranged in superstructures ranging from a $21 \times 21$ unit cell at $0.3 \mathrm{ML}$ to $9 \times 9$ at $0.8 \mathrm{ML}$ of Au visible in STM and LEED.

Nickel is well known for its use in catalysts for steam reforming of natural gas to syngas. ${ }^{10}$ In this large scale industrial process methane is dissociated all the way to carbon which is then oxidized to $\mathrm{CO}$. Alloying of a less reactive metal into the catalyst is expected to reduce the reactivity of the surface. In principle this is an unwanted effect in catalysis unless it is followed by improved selectivity or increased stability of the catalyst. It is, e.g., known that adding hydrogensulfide to the feed stock in the steam reforming process of natural gas, although sulfur strongly poisons the reactivity, is very useful for suppressing carbon filament formation in the so-called SPARG process. ${ }^{11,12}$

In the present work we have studied the reactivity of the $\mathrm{Au}$ surface alloyed $\mathrm{Ni}(111)$ system toward $\mathrm{CH}_{4}, \mathrm{CO}$, and $\mathrm{D}_{2}$. We find that the presence of $\mathrm{Au}$ in the topmost atomic surface layer has a significant effect on the chemical activity. Desorption energies of carbonmonoxid and deuterium are decreased and the sticking coefficient of $\mathrm{CH}_{4}$ is reduced. We observe a new weakly bonded deuterium chemisorption state. Also, as the Au coverage is increased, the binding of $\mathrm{CO}$ goes through a complex series of chemisorption phases reflecting the $\mathrm{CO}-\mathrm{CO}$ repulsion and the change in available surface sites. We apply an ensemble model based on the random nature of the surface alloy that accounts for the sticking of $\mathrm{CH}_{4}$ and the chemisorption of deuterium. This model also implies short range electronic perturbation due to $\mathrm{Au}$ in the vicinity of Ni sites.

\section{EXPERIMENT}

Details of the ultra high vacuum apparatus used in these experiments have previously been described. ${ }^{13}$ Briefly, it 
consists of a preparation section with a quadrupole mass spectrometer (QMS) prepared for temperature programmed desorption (TPD), a sputter gun, a gold evaporator and facilities to introduce gases onto the sample either by background pressure exposures or supersonic molecular beams. An analysis section separated from the preparation section by a large gate valve is equipped with Auger electron spectroscopy (AES), low energy electron diffraction (LEED) and high resolution electron energy loss spectroscopy (HREELS). Opposite the molecular beam source a time of flight (TOF) system calibrated as described in Ref. 13 enables measurement of the produced molecular beams. The crystal was mounted on two tungsten wires and could be heated resistively using a low voltage power supply and cooled with liquid nitrogen to $90 \mathrm{~K}$.

The Ni(111) sample spark cut from a single crystal Ni rod, diamond polished and aligned by Laue back reflection $\mathrm{x}$-ray diffraction to within $0.5^{\circ}$ of the (111) face was initially cleaned by $\mathrm{Ar}^{+}$sputtering, annealing at high temperature $(1573 \mathrm{~K})$, oxidation and reduction cycles until no contaminations were detectable with AES and a sharp 1×1 LEED pattern was observed.

$\mathrm{Au} / \mathrm{Ni}(111)$ surface alloys with various concentrations of gold was prepared by evaporating high purity gold (99.99\%) onto the cleaned and pure $\mathrm{Ni}(111)$ surface at $573 \mathrm{~K}$ with subsequent brief annealing to $773 \mathrm{~K}$. No impurities were ever detected by AES. Carbon deposited during experiments could be removed by gentle oxidation and reduction at $573 \mathrm{~K}$ without changing the surface alloy as observed with LEED and AES. The prepared sample could therefore be used for several experiments.

The high purity gases used for the beam experiments $\mathrm{He}$ (N60), $\mathrm{H}_{2}(\mathrm{~N} 60), \mathrm{CH}_{4}$ (N55) and $3 \% \mathrm{CH}_{4}$ in $\mathrm{He}$ (N55) were prior to expansion further cleaned by passing the gas mixtures through activated $\mathrm{Ni}$ and $\mathrm{Cu}$ catalysts at room temperature. Control experiments were carried out as described in Ref. 13 to check for artifacts originating from impurities in the gasses, or the formation of ethylene or other highly reactive species in the heated nozzle. None of these control experiments resulted in carbon deposition that would influence the measured sticking coefficients of $\mathrm{CH}_{4}$.

The CO (N47) and 99.9\% $\mathrm{D}_{2}$ used for background exposures were admitted to the chamber without further purification.

The AES signal for chemisorbed carbon was calibrated by saturating the clean $\mathrm{Ni}(111)$ surface using ethylene exposures at $473 \mathrm{~K}$. The saturation coverage of carbon on $\mathrm{Ni}(111)$ is $0.43 \mathrm{ML}$ as determined from the proposed structure in Refs. 14 and 15.

Gold coverages were determined from the differentiated AES spectra using the $\mathrm{I}[\mathrm{Au}(69 \mathrm{eV})] / \mathrm{I}[\mathrm{Ni}(848 \mathrm{eV})]$ peak ratio. Due to the nearby $\mathrm{Ni}(61 \mathrm{eV})$ peak only the high energy part of the Au peak was used to minimize interference from this Ni peak. Above 0.3 ML Au LEED patterns with dimensions reflecting the Au coverage were also determined. Using a relation between superstructure dimension and $\mathrm{Au}$ coverage determined from STM experiments ${ }^{9}$ this provided a calibration of the AES measurements. The relative uncertainty

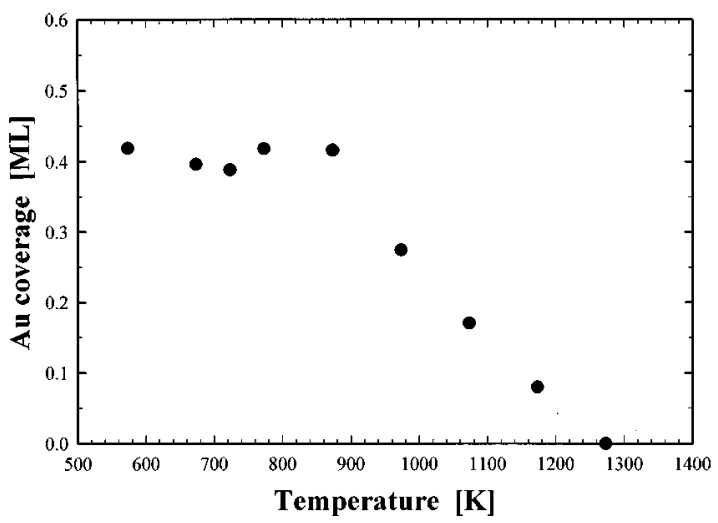

FIG. 1. Disappearance of Au from the surface region with increasing annealing temperature as determined by AES (see text for details).

on absolute $\mathrm{Au}$ coverages is estimated to $10 \%-15 \%$.

\section{RESULTS}

\section{A. Thermal stability of the surface alloy}

In investigations of the thermal stability of the $\mathrm{Au} /$ $\mathrm{Ni}(111)$ surface alloy we find that monolayers of Au diffuse into the bulk of the sample at high temperature. Although the phase diagram of gold and nickel ${ }^{16}$ exhibits a miscibility gap this does not mean that small amounts of Au cannot dissolve in Ni. However an activation barrier for diffusion into the bulk must be overcome.

After heating the sample to $1273 \mathrm{~K}$ initially deposited $\mathrm{Au}$ ( $\sim 4 \mathrm{ML})$ had almost disappeared as determined by AES. Attempts were made to desorb Au in TPD experiments, but Au was never detected in the mass spectrometer leading to the conclusion that Au diffuses into the bulk of the crystal. This conclusion was further confirmed by cleaning the initially annealed surface alloy to $1273 \mathrm{~K}$ by sputtering off the residual $\mathrm{Au}$ at room temperature. Although the surface was found clean, dissolved Au was found to segregate to the surface in appreciable amounts by annealing to $1073 \mathrm{~K}$ for 10 min.

The temperature at which the diffusion into the bulk becomes significant was found to be $850-900 \mathrm{~K}$ in the annealing experiment summarized in Fig. 1. In this experiment the sample initially having $0.4 \mathrm{ML}$ Au deposited in the surface was ramped up $(2 \mathrm{~K} / \mathrm{s})$ from $473 \mathrm{~K}$ to the temperature given on the temperature axis for a few seconds and then cooled down again to $473 \mathrm{~K}$, where the Au coverage was measured by AES.

\section{B. $\mathrm{CH}_{4}$ dissociation}

The sticking coefficient of $\mathrm{CH}_{4}$ on the surface alloys of different $\mathrm{Au}$ coverage was obtained from the carbon uptake versus exposure of $\mathrm{CH}_{4}$ from molecular beams of fixed translational and vibrational energy. Two different beams was used: (1) a vibrationally hot beam $\left(3 \% \mathrm{CH}_{4}\right.$ in $\left.\mathrm{He}\right)$ with $T_{\text {vib }}=1050 \mathrm{~K}$ and $E_{\text {trans }}=74 \mathrm{~kJ} / \mathrm{mole}$ and 2) a vibrationally cold beam $\left(3 \% \mathrm{CH}_{4}\right.$ in $\left.\mathrm{H}_{2}\right)$ with $T_{\mathrm{vib}}=550 \mathrm{~K}$ and $E_{\text {trans }}=77$ $\mathrm{kJ} / \mathrm{mole}$. During exposures the crystal was kept at $473 \mathrm{~K}$ and 


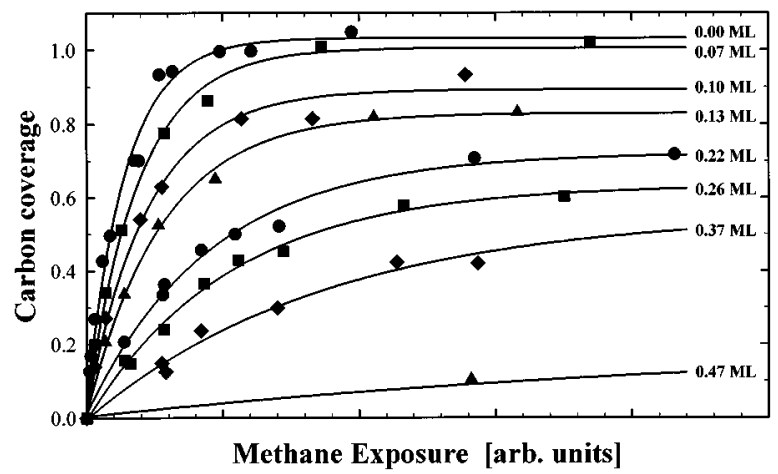

FIG. 2. Deposition of carbon on $\mathrm{Au} / \mathrm{Ni}(111)$ surface alloys of different $\mathrm{Au}$ coverage as indicated in the figure following dissociation of $\mathrm{CH}_{4}$ incident at constant $T_{\text {vib }}=1050 \mathrm{~K}$ and $E_{\text {trans }}=74 \mathrm{~kJ} / \mathrm{mole}$. Solid lines are fit to the data using a first-order adsorption model assuming island formation.

all hot filaments in the chamber were switched off. Figure 2 shows the uptake curves for the vibrationally hot beam for several Au coverages. The average initial sticking coefficient and the saturation level of carbon uptake is reduced with increasing Au coverage.

Chemisorption of carbon on the $\mathrm{Ni}(111)$ surface is associated with a "clock" reconstruction ${ }^{14,15}$ very similar to that on the $\mathrm{Ni}(100)$ surface. ${ }^{15,17}$ The characteristic LEED pattern of this structure ${ }^{14,15,18}$ corresponding to $0.43 \mathrm{ML}$ local coverage was observed following carbon deposition from $\mathrm{CH}_{4}$ exposures. On $\mathrm{Ni}(111)$ this reconstruction is associated with island formation already at very low coverages. The carbon uptake following $\mathrm{CH}_{4}$ exposures of intensity $\Phi$ in $\mathrm{ML} / \mathrm{s}$ was therefore modeled by first-order adsorption kinetics:

$$
\frac{d \theta_{C}}{d t}=S_{0}^{\prime} \Phi\left(\theta_{C, \mathrm{sat}}-\theta_{C}\right),
$$

where $\theta_{C \text {,sat }}$ is a carbon saturation level that depends on $\mathrm{Au}$ coverage and $S_{0}^{\prime}$ is the sticking coefficient corresponding to the fraction of surface area that can chemisorb carbon for a given Au coverage. The average sticking coefficient on the surface alloy (the initial slope of the uptake curves) is $S_{\text {avg }}$ $=S_{0}^{\prime} \theta_{C, \text { sat }}$.

Integration of this equation leads to

$$
\theta_{C}(\Phi t)=\theta_{C, \text { sat }}\left[1-\exp \left(-S_{0}^{\prime} \Phi t\right)\right]
$$

which was fit to the experimental data with $S_{0}^{\prime}$ and $\theta_{C \text {,sat }}$ as free parameters. These fitted curves are shown by solid lines in Fig. 2, where the carbon coverage is measured relative to the saturation coverage on $\mathrm{Ni}(111)$ with no Au present. The model is seen to describe the experimental data very well.

The carbon saturation level, $\theta_{C \text {,sat }}$, relative to saturation on pure $\mathrm{Ni}(111)$ is as shown in Fig. 3 approximately linearly related to the Au coverage for $\theta_{\mathrm{Au}}<0.4 \mathrm{ML}$. A linear regression through these data gives: $\theta_{C \text {,sat }}=1.00-1.37 \theta_{\mathrm{Au}}$, meaning that one $\mathrm{Au}$ atom alloyed into the surface on average blocks approximately 1.4 carbon chemisorption sites $(3.3 \mathrm{Ni}$ atoms).

The initial sticking coefficient, $S_{\text {avg }}$, is influenced by the presence of the gold as seen in Fig. 4 which shows the av-

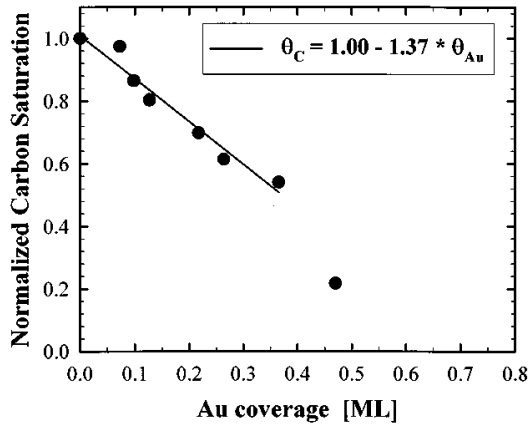

FIG. 3. Decrease in saturation coverage of carbon with increasing Au coverage normalized to saturation coverage on pure $\mathrm{Ni}(111)$. On average one $\mathrm{Au}$ atom blocks 1.4 carbon chemisorption sites as determined from the linear fit through the data shown by solid line.

erage initial sticking coefficient normalized to the initial sticking coefficient on the clean $\mathrm{Ni}(111)$ surface vs Au coverage for the vibrationally cold and hot beam. Initially, the sticking coefficient decreases with a slope suggesting that during the dissociation one Au atom blocks an area corresponding to the substituted $\mathrm{Ni}$ atom and its six nearest neighbors. This also implies that $\mathrm{Au}$ atoms block more surface area during the dissociation process than the surface area required for chemisorption of carbon. It is seen that the influence of $\mathrm{Au}$ on the sticking coefficients determined for the vibrationally hot $\mathrm{CH}_{4}$ is less than for for the vibrationally cold $\mathrm{CH}_{4}$. The solid lines are calculated using a model described in the discussion section.

Finally, the initial sticking coefficient of $\mathrm{CH}_{4}$ at normal incidence on pure $\mathrm{Ni}(111)$ vs translational energy was measured using seeded beams of the same vibrational temperatures $(550$ and $1050 \mathrm{~K})$ as used in determining sticking coefficients on the $\mathrm{Au}$ alloyed $\mathrm{Ni}(111)$ surfaces. Absolute values were calibrated as described in Ref. 13 and results are shown in Fig. 5. A dramatic effect of both the translational energy and vibrational excitation of the incident $\mathrm{CH}_{4}$ characteristic of activated direct dissociative chemisorption is seen. The amplitude of this effect is comparable to that ob-

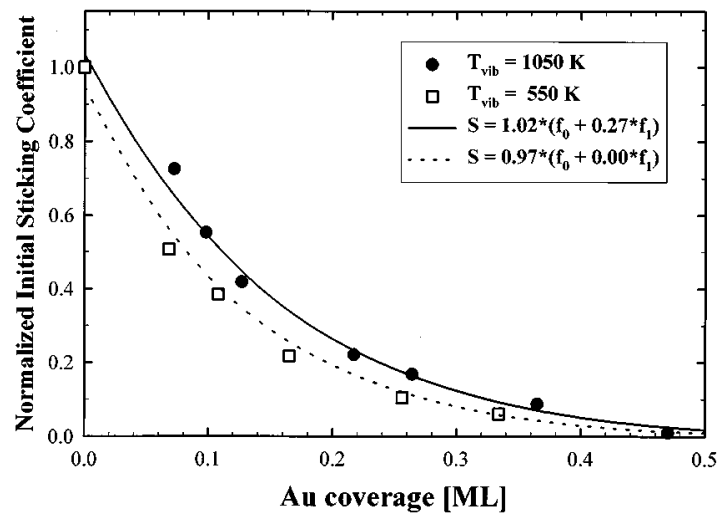

FIG. 4. Initial sticking coefficient of $\mathrm{CH}_{4}$ as function of $\mathrm{Au}$ coverage normalized to the initial sticking coefficient on pure $\mathrm{Ni}(111)$. Data are shown for methane of two vibrational temperatures but nearly equal translational energy. The solid and dashed line are a model described in the text. 


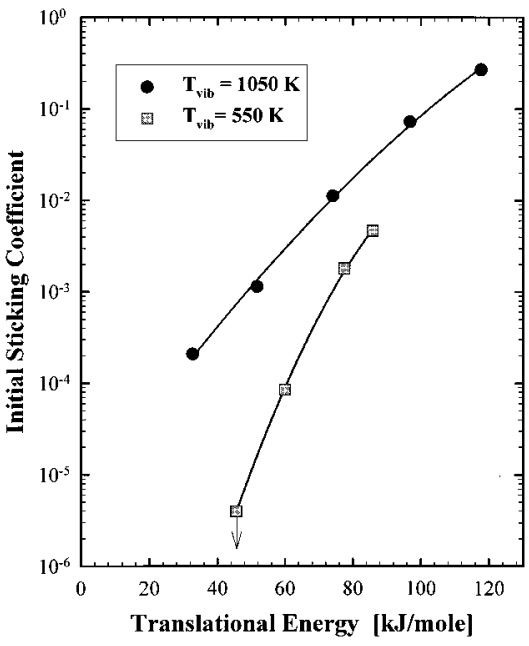

FIG. 5. Initial sticking coefficient $\mathrm{CH}_{4}$ on pure $\mathrm{Ni}(111)$ as function of translational energy for two vibrational temperatures. The data point with an arrow attached represents an upper limit for the sticking coefficient at these conditions. Lines through measurements have no theoretical significance.

served on $\mathrm{Ni}(100)^{13}$ whereas the absolute sticking coefficients on the $\mathrm{Ni}(111)$ are approximately a factor of 10 lower than on $\mathrm{Ni}(100)$ at the low translational energies but similar at high energy. ${ }^{13}$

The present results are in excellent agreement with the previous measurements of Lee et al. ${ }^{19}$ Our vibrationally hot beam is hotter than the hottest beams and our cold beam is colder than the coldest beams used in their experiments. The data in Fig. 5 therefore envelope the data of Lee et al.

\section{CO and $D_{2}$ adsorption}

The reactivity of the $\mathrm{Au} / \mathrm{Ni}(111)$ surface alloy toward $\mathrm{CO}$ and $\mathrm{D}_{2}$ was studied as a function of Au coverage. Figures 6 and 7 show TPD spectra of saturation coverages of carbonmonoxid and deuterium respectively for different $\mathrm{Au}$ coverages. All spectra was obtained with a heating rate of 2 $\mathrm{K} / \mathrm{s}$.

The $\mathrm{CO}$ was adsorbed from an background pressure of $4 \times 10^{-5} \mathrm{~Pa}$ for approximately $10 \mathrm{~min}$, as the sample was cooled from 473 to $103 \mathrm{~K}$. The spectrum for the pure $\mathrm{Ni}(111)$ surface appears as previously reported in the literature and corresponds to $0.57 \mathrm{ML}$ of $\mathrm{CO} .{ }^{20}$ As the Au coverage increases the saturation coverage of chemisorbed $\mathrm{CO}$ at the conditions described decreases as shown in the insert of Fig. 6. A peak appears in the region $320-340 \mathrm{~K}$ at $0.40 \mathrm{ML}$ with diminishing amplitude as $\mathrm{Au}$ is added to the surface alloy and a feature is seen at the lowest temperature in the spectrum above $0.6 \mathrm{ML}$ of Au.

Deuterium was dissociated on the $\mathrm{Au} / \mathrm{Ni}(111)$ surface alloys exposing the sample to $7 \times 10^{-3} \mathrm{~Pa}$ of $\mathrm{D}_{2}$ for $15 \mathrm{~min}$ as the sample was cooled from 473 to $103 \mathrm{~K}$ corresponding to saturation of the surface alloys. On the pure $\mathrm{Ni}(111)$ surface the double feature reported in the literature attributed to 1.0 ML chemisorbed deuterium ${ }^{21,22}$ is seen in Fig. 7. The double feature is asymmetric with the low temperature peak being slightly higher as also observed in Ref. 22 but not in Ref. 21.

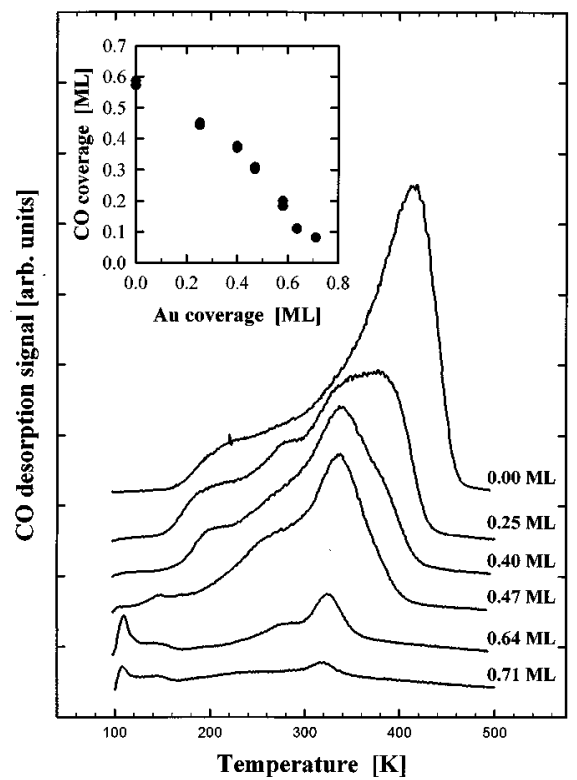

FIG. 6. TPD spectra of $\mathrm{CO}$ from $\mathrm{Au} / \mathrm{Ni}(111)$ surface alloys with Au coverages as indicated. The surface alloys were exposed to $\mathrm{CO}$ until saturation at $T_{\text {crystal }}=103 \mathrm{~K}$. The insert shows the saturation coverage of chemisorbed CO as function Au coverage.

A new TPD feature reflecting the influence of $\mathrm{Au}$ in the $\mathrm{Ni}(111)$ surface is evident in the TPD spectra of $\mathrm{D}_{2}$. As the $\mathrm{Au}$ coverage is increased the features related to the pure $\mathrm{Ni}(111)$ surface at around 340 and $375 \mathrm{~K}$ are clearly attenuated and shifted down in temperature at $\theta_{\mathrm{Au}}>0.15 \mathrm{ML}$. At the same time another feature related to the presence of $\mathrm{Au}$ in the topmost atomic surface layer builds up in the region $180-220 \mathrm{~K}$ until $\theta_{\mathrm{Au}} \sim 0.3-0.4 \mathrm{ML}$ and then gradually disappears again as the $\mathrm{Au}$ concentration approaches the maximum concentration of $\theta_{\mathrm{Au}} \simeq 0.8 \mathrm{ML}$.

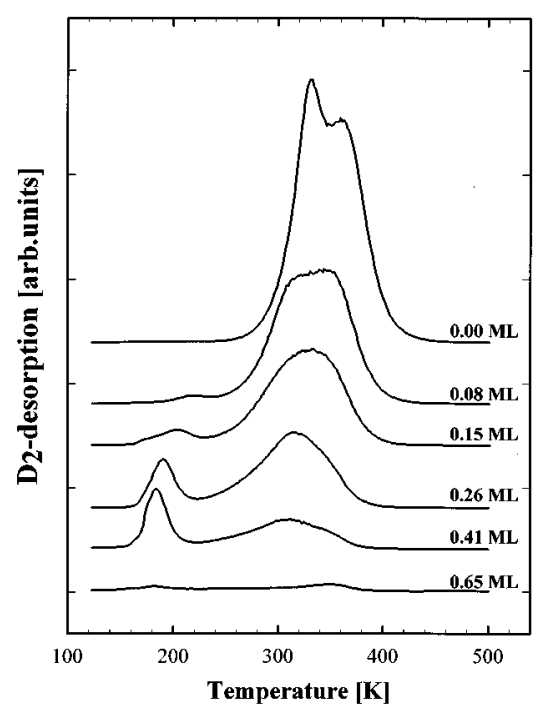

FIG. 7. TPD spectra of $D_{2}$ from $A u / N i(111)$ surface alloys with $A u$ coverages as indicated. The surface alloys were exposed to $D_{2}$ until saturation at $T_{\text {crystal }}=103 \mathrm{~K}$. 


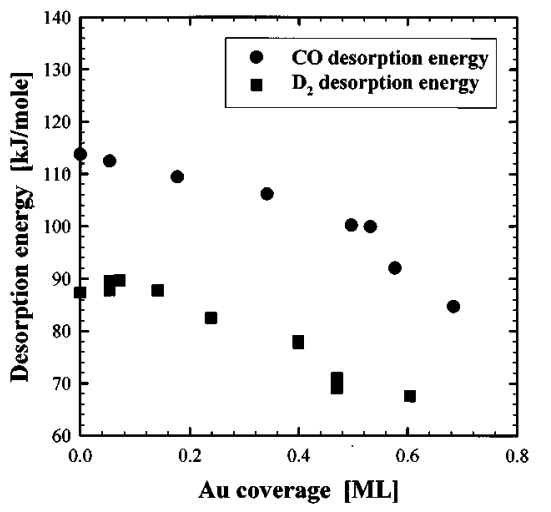

FIG. 8. Desorption energies as determined by Redhead analysis of TPD spectra obtained for low coverages of $\mathrm{CO}$ (solid circles) and $\mathrm{D}_{2}$ (solid squares) as function $\mathrm{Au}$ coverage in the $\mathrm{Au} / \mathrm{Ni}(111)$ surface alloy.

Figure 8 shows desorption energies for $\mathrm{CO}$ and $\mathrm{D}_{2}$ as determined from low coverage $(\leqslant 0.1 \mathrm{ML})$ TPD spectra using Redhead analysis with a pre-exponential factor of $10^{13}$ $\mathrm{s}^{-1}$. The desorption energies decreases with increasing $\mathrm{Au}$ coverage by approximately $25-30 \mathrm{~kJ} / \mathrm{mole}$ as the Au coverage in increased from 0.0 to $0.7 \mathrm{ML}$.

\section{DISCUSSION}

Our experiments clearly demonstrate that the presence of $\mathrm{Au}$ in the topmost atomic layer of the Ni(111) surface perturb the chemical activity. The binding energy of chemisorbed carbonmonoxid and deuterium and the ability to dissociate $\mathrm{CH}_{4}$ are reduced. We find that this can be accounted for by ensemble effects within a model of random statistics for surface clusters of $\mathrm{Ni}$ and $\mathrm{Au}$ atoms including also electronic perturbations on $\mathrm{Ni}$ sites close ( 1 or 2 nearest neighbor) to Au sites.

From calculations ${ }^{23-26}$ it has been found that the minimum energy path for $\mathrm{CH}_{4}$ dissociation on $\mathrm{Ni}$ is the on top site. It is to be expected that the barrier on a $\mathrm{Au}$ atom is substantially higher than on $\mathrm{Ni}$ so that $\mathrm{CH}_{4}$ dissociation on top of a $\mathrm{Au}$ atom is essentially impossible. As already mentioned the dissociation of $\mathrm{CH}_{4}$ is reduced on the $\mathrm{Au}$ alloyed Ni(111) surface. The initial slope suggests a simple site blocking mechanism where the area corresponding to a $\mathrm{Au}$ atom and its six nearest-neighbor atoms become chemically inert. The implication that $\mathrm{Au}$ atoms alloyed into the surface perturb the six nearest-neighbor (Ni) atoms can also be seen on STM images, ${ }^{5,9}$ where $\mathrm{Ni}$ atoms surrounding $\mathrm{Au}$ atoms clearly appear different than $\mathrm{Ni}$ with only Ni nearest neighbors.

From the STM experiments ${ }^{5,9}$ it is known that the distribution of $\mathrm{Au}$ and $\mathrm{Ni}$ atoms in the surface alloy is very close to being random. It is therefore appealing and relevant to approximate the distribution by a random one and apply a mean field model for the probabilities of different ensembles of surface atoms. In this model the probability that an incident $\mathrm{CH}_{4}$ will hit a $\mathrm{Ni}$ atom in the surface alloy having only $\mathrm{Ni}$ as nearest neighbors is $\left(1-\theta_{\mathrm{Au}}\right) .^{7}$ The Au coverage dependence of the initial sticking coefficient therefore becomes

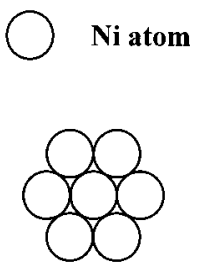

(a)
Au atom

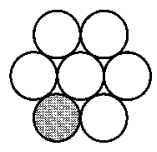

(b)
FIG. 9. Model dissociation sites for $\mathrm{CH}_{4}$ (a) with only Ni nearest neighbors and and sticking coefficient $S_{0}$ and (b) with one Au and five Ni nearest neighbors and sticking coefficient $S_{1}$.

$$
S_{\text {avg }}=S_{0}\left(1-\theta_{\mathrm{Au}}\right)^{7},
$$

where $S_{0}$ is the sticking coefficient on a $\mathrm{Ni}$ atom with only Ni nearest neighbors. This expression leads to a very good description of the measured initial sticking probabilities of the vibrationally cold methane. However, there are deviations for the vibrational hot methane, the sticking coefficient systematically being slightly higher than predicted by this model. As observed in previous experiments ${ }^{19}$ and seen in Fig. 5 of this work, the dissociation is dramatically enhanced as the vibrational energy of the incident $\mathrm{CH}_{4}$ is increased. It is reasonable to expect that vibrationally hot $\mathrm{CH}_{4}$ is less sensitive to changes in the height of the energy barrier to dissociation. In terms of S-shaped sticking curves resolved on vibrational excitation as recently applied to $\mathrm{CH}_{4}$ on $\mathrm{Ni}(100)^{13,27}$ this means that the translational energy of the $\mathrm{CH}_{4}$ lies above the threshold for dissociation of vibrationally excited $\mathrm{CH}_{4}$ where the sticking probability is nearly constant. Therefore, a change in the threshold (change in effective barrier height) does not change the sticking probability of the vibrationally excited $\mathrm{CH}_{4}$. The weaker influence of $\mathrm{Au}$ on the average sticking probability of the vibrationally hot $\mathrm{CH}_{4}$ therefore reflect the higher population of vibrationally excited modes.

If we also include the possibility of dissociation on $\mathrm{Ni}$ on top sites with one $\mathrm{Au}$ and $5 \mathrm{Ni}$ neighbors the average sticking coefficient will in the mean field random model be given by

$$
S_{\mathrm{avg}}=S_{0}\left[\left(1-\theta_{\mathrm{Au}}\right)^{7}+S_{1} / S_{0} \cdot 6 \cdot \theta_{\mathrm{Au}}\left(1-\theta_{\mathrm{Au}}\right)^{6}\right],
$$

where we have introduced, $S_{1}$, the sticking coefficient on a $\mathrm{Ni}$ atom with one $\mathrm{Au}$ and five $\mathrm{Ni}$ atoms as nearest neighbors. The two dissociation sites considered are sketched in Fig. 9.

However, atomically resolved STM pictures of the surface alloys at various $\mathrm{Au}$ coverages have been available. Therefore experimentally determined statistics for the ensembles considered can be used instead of the mean field model. This is implemented by functions $f_{0}\left(\theta_{\mathrm{Au}}\right)$ and $f_{1}\left(\theta_{\mathrm{Au}}\right)$ fit to the STM results, ${ }^{5,9}$ where $f_{0}$ and $f_{1}$ are the fraction of $\mathrm{Ni}$ atoms with zero and one $\mathrm{Au}$ nearest neighbor, respectively. A very good description is obtained when fitting the model

$$
S=S_{0}\left[f_{0}\left(\theta_{\mathrm{Au}}\right)+S_{1} / S_{0} \cdot f_{1}\left(\theta_{\mathrm{Au}}\right)\right]
$$


to the measured data shown in Fig. 4. The parameters obtained are for the high vibrational energy beam: $S_{0}=1.02$ and $S_{1}=(0.27 \pm 0.06) S_{0}$. For the vibrationally cold $\mathrm{CH}_{4}$ we find: $S_{0}=0.97$ and $S_{1}=(0.00 \pm 0.06) S_{0}$. The uncertainties are standard deviations and the fits are shown by solid lines in Fig. 4.

Parameters only slightly different is found if instead the simpler mean field random model of Eq. (4) is used. Therefore, the appealing and commonly applied mean field model type is applicable to the $\mathrm{Au} / \mathrm{Ni}(111)$ system although this does not necessarily have to be the case in general for other systems.

Recently Kratzer et al. have calculated the changes in the height of the dissociation barrier on the $\mathrm{Ni}$ on top site when Au atoms are present as nearest neighbors. ${ }^{26}$ They find that on a $\mathrm{Ni}$ atom with one $\mathrm{Au}$ and $5 \mathrm{Ni}$ atoms as nearest neighbors the barrier is increased by approximately $0.17 \mathrm{eV}$ $(16 \mathrm{~kJ} / \mathrm{mole})$, whereas two Au atoms give an increase of 0.39 $\mathrm{eV}(38 \mathrm{~kJ} / \mathrm{mole})$ which makes this configuration essentially inactive. Now, looking at how the sticking coefficient depends on the translational energy for fixed vibrational temperature as shown in Fig. 4, we can use the calculated changes in barrier height to determine corresponding values of $S_{1} / S_{0}$ for the two vibrational energies. Doing so, we assume for fixed vibrational energy that an increase in the dissociation barrier height is equivalent to a decrease in translational energy on the sticking curves shown in Fig. 4. From Fig. 5 we then find $S_{1}=0.22 S_{0}$ for the high vibrational energy $\mathrm{CH}_{4}$ and $S_{1}=0.07 S_{0}$ for the cold $\mathrm{CH}_{4}$ in good agreement with the fitted values. ${ }^{5}$

Figure 3 shows how the saturation coverage of carbon on the surface alloys decreases with increasing Au coverage. Applying an ensemble model to account for chemisorption sites is difficult. Carbon chemisorption on pure $\mathrm{Ni}(111)$ is associated with a reconstruction that transform the surface into a structure very much like the reconstructed $\mathrm{C} / \mathrm{Ni}(100) .{ }^{14,15}$ The reconstruction is driven by the tendency of carbon to increase the $\mathrm{Ni}$ coordination number. We observed this reconstruction on the pure $\mathrm{Ni}(111)$ by a sharp LEED pattern characteristic of this structure. Even with 0.12 ML $\mathrm{Au}$ in the surface a diffuse LEED pattern of this reconstruction could still be seen. However, on the surface alloys carbon might also chemisorb without reconstructing the surface. Due to the lack of detailed information about carbon chemisorption sites on the $\mathrm{Au} / \mathrm{Ni}(111)$ surface alloy our data do not allow for modeling the carbon chemisorption using ensemble statistics as applied above. However, on average Au blocks 1.4 carbon chemisorption sites as determined by the linear regression through the data of Fig. 3.

The effect of alloying Au into the $\mathrm{Ni}(111)$ surface is also seen in the TPD spectra of $\mathrm{D}_{2}$ shown in Fig. 7. As the double feature at 340 and $375 \mathrm{~K}$ is attenuated and shifted down in temperature with increasing $\mathrm{Au}$ concentration a new feature develops at around 180-220 K and then disappears again at higher Au concentration. This is also shown in Fig. 10 where the peak areas of the low temperature peak and the high temperature peaks are plotted against $\mathrm{Au}$ coverage. It is tempting to apply the mean field model to relate ensembles of chemisorption sites to the appearance and disappearance

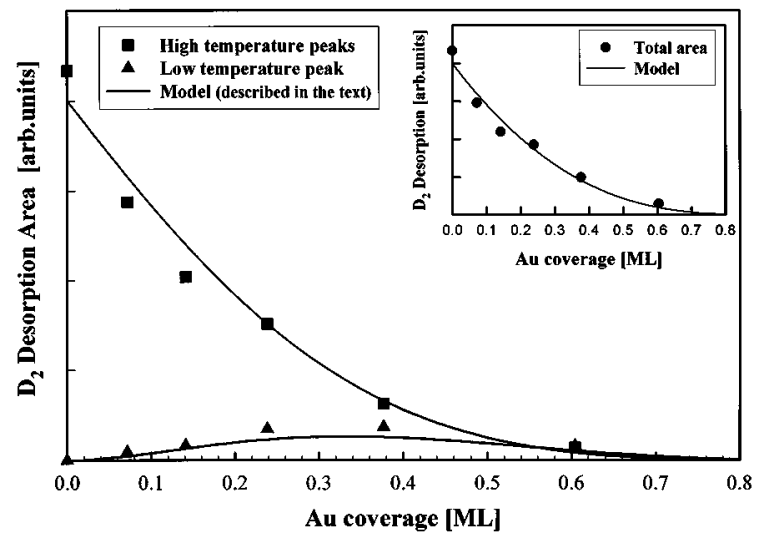

FIG. 10. Area of the $\mathrm{D}_{2}$ low temperature peak (solid triangles) and high temperature peaks (solid squares) of figure 6 as function of $\mathrm{Au}$ coverage. The insert shows total desorption area vs Au coverage. Solid lines are a model described the text.

of the peaks in the TPD spectra of chemisorbed deuterium. Deuterium (or hydrogen) chemisorb optimal in hollow sites on clean $\mathrm{Ni}(111) .{ }^{28}$ In the plausible model suggested below it is assumed that deuterium also on the alloy surface occupies hollow sites and that the honeycomb structure observed on the clean $\mathrm{Ni}(111)$ surface (or adsorbate-adsorbate interaction) is of less importance, especially as the total coverage decreases. The chemisorption site corresponding to the low temperature peak must clearly involve Ni since it disappears at high $\mathrm{Au}$ concentrations. A surface cluster consisting of a hollow site surrounded by six atoms arranged in a triangle enables us to describe the magnitude of the peaks. The fraction of hollow sites on the surface alloy with six $\mathrm{Ni}$ atoms is in the mean-field random model: $\left(1-\theta_{\mathrm{Au}}\right)^{6}$. We now assume that one second nearest neighbor $\mathrm{Au}$ atom will not perturb the electronic structure at the hollow site sufficiently to make it distinguishable in the TPD spectra from a hollow site only surrounded by $\mathrm{Ni}$ atoms. If one of the corner atoms is allowed to be Au the probability for any of these configurations shown in Fig. 11(a) is

$$
A_{\text {high }}=\left(1-\theta_{\mathrm{Au}}\right)^{6}+3 \theta_{\mathrm{Au}}\left(1-\theta_{\mathrm{Au}}\right)^{5} \text {. }
$$

We assign this type of sites to be related to the high temperature TPD features. If however two corner atoms is

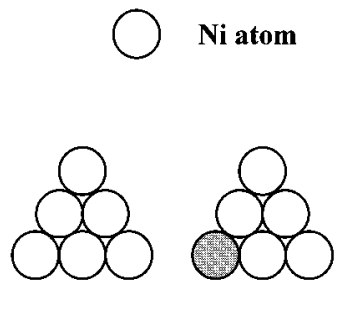

(a)

\section{Au atom}

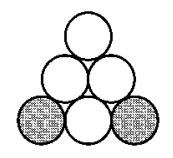

(b)
FIG. 11. Model hollow sites for chemisorption of deuterium: (a) sites related to the high temperature peaks and (b) site perturbed by the presence of Au corresponding to weakly chemisorbed deuterium in the low temperature desorption feature in Fig. 7. 
$\mathrm{Au}$ as illustrated in Fig. 11(b) this is assigned to the weakly bonded deuterium desorbing at low temperature. The fraction of such sites is given by

$$
A_{\text {low }}=3 \theta_{\mathrm{Au}}^{2}\left(1-\theta_{\mathrm{Au}}\right)^{4} \text {. }
$$

All other configurations are in this model considered not to enable chemisorption of deuterium or to result in bonding weaker than observable at the adsorption conditions in the experiment. These two expressions, Eqs. (6) and (7), are plotted without any fitting as solid lines in Fig. 10. Clearly, the behavior of the peak areas are very nicely described by this very simple model.

Also in the TPD spectra of CO shown in Fig. 6 the influence of the $\mathrm{Au}$ in the $\mathrm{Ni}(111)$ surface is clearly seen. The saturation coverage of $\mathrm{CO}$ decreases with increasing $\mathrm{Au}$ coverage as shown in the insert of the figure. The decrease in binding energy of $\mathrm{CO}$ as shown in Fig. 8 is also reflected in the saturation spectra of Fig. 6 where a down shift in temperature is clearly seen. The distinct feature appearing around $340 \mathrm{~K}$ above $\mathrm{Au}$ coverages of $0.25 \mathrm{ML}$ is probably related to $\mathrm{CO}$ bonding to a site involving $\mathrm{Ni}$ atoms perturbed by the presence of $\mathrm{Au}$ since, the amplitude of this feature decreases linearly with increasing $\mathrm{Au}$ coverage correlated with the disappearance of Ni sites available for bonding. Interpretation of this feature in terms of an ensemble model is difficult since the peak is not sufficiently resolved from the rest of the spectrum. Also complications due to $\mathrm{CO}-\mathrm{CO}$ repulsion most likely is of major importance for the desorption kinetics. At Au coverages above $0.6 \mathrm{ML}$ a part of a feature is seen in the spectra at the very low temperature region just above $100 \mathrm{~K}$ probably related to $\mathrm{CO}$ chemisorbed on effectively Au-like areas on the surface.

\section{CONCLUSION}

The effect of alloying $\mathrm{Au}$ into the Ni(111) surface has been determined for the influence on $\mathrm{CH}_{4}$ dissociation and chemisorption of $\mathrm{CO}$ and $\mathrm{D}_{2}$. The overall initial sticking coefficient is reduced as the coverage of $\mathrm{Au}$ is increased in a way that are accounted for by an ensemble model for dissociation sites involving $\mathrm{Ni}$ atom with different surroundings. Statistics for this is well described by a mean field model, however better, an improved description is obtained by using the experimentally determined distributions. The dissociation probability on a $\mathrm{Ni}$ atom with one $\mathrm{Au}$ atom and five $\mathrm{Ni}$ atoms as nearest neighbors is reduced relative to that on a $\mathrm{Ni}$ atom having only $\mathrm{Ni}$ as nearest neighbors by a factor depending on the vibrational temperature of the incident $\mathrm{CH}_{4}$. This is reflected in the dependence of the sticking coefficient of vibrationally hot and cold $\mathrm{CH}_{4}$ vs translational energy on the clean $\mathrm{Ni}(111)$ when an increase in energy barrier to dissociation is assumed equivalent to a decrease in translational energy.

The saturation coverage of carbonmonoxid and deuterium is decreased with increasing $\mathrm{Au}$ coverage as consequence of decreasing desorption energy of the strongest bonded species. A new clearly separated desorption state for
$\mathrm{D}_{2}$ is observed by TPD at $180-220 \mathrm{~K}$ probably related to a chemisorption site involving both $\mathrm{Au}$ and $\mathrm{Ni}$. Also in the case of $\mathrm{CO}$ new states are present.

Finally it is found that the $\mathrm{Au} / \mathrm{Ni}(111)$ surface alloys are stable up to $850-900 \mathrm{~K}$. Above this temperature $\mathrm{Au}$ is dissolving into the bulk of the Ni sample rather than desorbing.

\section{ACKNOWLEDGMENTS}

The authors would like to thank L. Pleth Nielsen for additional information and discussions on their STM experiments. Also P. Kratzer, B. Hammer, and J. K. Nørskov are acknowledged for inspiring discussions. This work was supported by the Danish Research Councils through the Center for Surface Reactivity.

${ }^{1}$ G. A. Somorjai, Introduction to Surface Chemistry and Catalysis (Wiley, New York, 1994).

${ }^{2}$ J. H. Sinfelt, Bimetallic Catalyst (Wiley, New York, 1983), 0-47188321-2.

${ }^{3}$ V. Ponec, Adv. Catal. 32, 149 (1983)

${ }^{4}$ W. H. Sachtler and R. A. van Santen, Adv. Catal. 26, 69 (1977).

${ }^{5}$ P. M. Holmblad, J. Hvolbæk Larsen, I. Chorkendorff, L. Pleth Nielsen, F. Besenbacher, I. Stensgaard, E. Lægsgaard, P. Kratzer, B. Hammer, and J. K. Nørskov (in preparation).

${ }^{6}$ L. Pleth Nielsen, F. Besenbacher, I. Stensgaard, E. Lægsgaard, C. Engdahl, P. Stoltze, K. W. Jacobsen, and J. K. Nørskov, Phys. Rev. Lett. 71, 754 (1993).

${ }^{7}$ L. Pleth Nielsen, I. Stensgaard, E. Lægsgaard, and F. Besenbacher, Surf. Sci. 307, 544 (1994).

${ }^{8}$ J. Jacobsen, L. Pleth Nielsen, F. Besenbacher, I. Stensgaard, E. Lægsgaard, T. Rasmussen, K. W. Jacobsen, and J. K. Nørskov, Phys. Rev. Lett. 75, 489 (1995).

${ }^{9}$ L. Pleth Nielsen, F. Besenbacher, E. Lægsgaard, and I. Stensgaard, Ph.D. thesis, Institute of Physics and Astronomy, University of Aarhus, Denmark, 1996.

${ }^{10}$ J. R. Rostrup-Nielsen, Catalytic Steam Reforming (Springer, Berlin, 1984).

${ }^{11}$ J. R. Rostrup-Nielsen and I. Alstrup, Proc. 10th North Am. Meeting of Catalysis Soc., 725 (1987).

${ }^{12}$ J. R. Rostrup-Nielsen, J. Catal. 85, 31 (1984).

${ }^{13}$ P. M. Holmblad, J. Wambach, and I. Chorkendorff, J. Chem. Phys. 102, 8255 (1995).

${ }^{14}$ C. Klink, I. Stensgaard, F. Besenbacher, and E. Lægsgaard, submitted to Surf. Sci.

${ }^{15} \mathrm{C}$. Klink, Ph.D. thesis, Institute of Physics and Astronomy, University of Aarhus, Denmark, 1994

${ }^{16}$ T. B. Massalski et al., Binary Alloy Phase Diagrams, 2nd ed. (American Society for Metals, Metals Park, Ohio, 1990).

${ }^{17}$ C. Klink, L. Olesen, F. Besenbacher, I. Stensgaard, E. Lægsgaard, and N. D. Lang, Phys. Rev. Lett. 71, 4350 (1993).

${ }^{18}$ D. E. Gardin, J. D. Batteas, M. A. Van Hove, and G. A. Somorjai, Surf. Sci. 296, 25 (1993)

${ }^{19}$ M. B. Lee, Q. Y. Yang, and S. T. Ceyer, J. Chem. Phys. 87, 2724 (1987).

${ }^{20}$ L. Surnev, Z. Xu, and J. T. Yates, Jr., Surf. Sci. 201, 1 (1988).

${ }^{21}$ J. N. Russell, Jr., I. Chorkendorff, A.-M. Lanzillotto, M. D. Alvey, and J. T. Yates, Jr., J. Chem. Phys. 85, 6186 (1986).

${ }^{22}$ A. D. Johnson, K. J. Maynard, S. P. Daley, Q. Y. Yang, and S. T. Ceyer, Phys. Rev. Lett. 67, 927 (1991).

${ }^{23}$ J. Schüle, P. Siegbahn, and U. Wahlgren, J. Chem. Phys. 89, 6982 (1988).

${ }^{24}$ H. Yang and J. L. Whitten, J. Chem. Phys. 96, 5529 (1992).

${ }^{25}$ H. Burghraef, A. P. J. Jansen, and R. A. van Santen, J. Chem. Phys. 98, 8810 (1993)

${ }^{26}$ P. Kratzer, B. Hammer, and J. K. Norskov (to be published).

${ }^{27}$ A. C. Luntz, J. Chem. Phys. 102, 8264 (1995).

${ }^{28}$ L. Hammer, H. Landskron, W. Nichtl-Pecher, A. Fricke, K. Heinz, and K. Muller, Phys. Rev. B 47, 15969 (1993) 